\title{
Treatment Strategies for Alzheimer's Disease
}

\author{
S. Gauthier, M.D., F.R.C.P.(C.) ${ }^{*}$
}

\section{INTRODUCTION}

This review will emphasize what has been learned on the drug treatment of Alzheimer's disease (AD) over the last twenty years. It assumes that the reader has already a working knowledge of the clinical symptoms and signs of this condition as well as its diagnosis and global management, recently summarized in (1) and (2).

\section{CHOLINERGIC REPLACEMENT THERAPY}

The treatment of $\mathrm{AD}$ has progressed since the late 1970s to a transmitter replacement strategy, based on the knowledge of a significant deficit in acetylcholine content in structures such as the Nucleus Basalis of Meynert, the hippocampus and the associative cortical areas. This deficit is associated with severe reduction in choline acetyl-transferase activity and relative sparing of post-synaptic muscarinic (M1) receptors (3). Acetylcholinesterase (AChE) is the predominant brain enzyme responsible for the catabolism of synaptic acetylcholine. Inhibition of AChE with cholinesterase inhibitors (CI) increases the half-life of acetylcholine in the synapse, thereby augmenting the receptor mediated post-synaptic signal (4).

The principles of acetylcholine replacement in $\mathrm{AD}$ are similar to the dopamine replacement in Parkinson's disease (PD). Table 1 provides a list of the mechanisms of action of drugs specifically targeting acetylcholine and dopamine synaptic activity, with examples of some of the drugs that have been tested or that are in use.

Much has been learned in terms of trial designs and choice of outcome variables for $\mathrm{AD}$ over the last twenty years. For example the CI tacrine was tested in eastern Canada using a cross-over design where all patients were exposed to drug and placebo in a

* To whom correspondence should be addressed: Alzheimer's Disease Research Unit, McGill Centre for Studies in Aging, 6825 LaSalle Blvd., Verdun, QC, Canada H4H 1R3 randomized sequence (5). It was found that there is a carry-over effect of the drug even after a full month of wash out, and that patients are deteriorating even within the time frame of the study: the parallel group design became the standard trial design for symptomatic drug development (6). Even negative studies in terms of efficacy on primary outcome variables such as the Alzheimer's Disease Assessment Scale-Cognitive Subscale (ADAS-Cog) and the Clinical Global Impression of Change (CGIC) were published and discussed in terms of missing a clinically important effect by using the wrong instruments (7).

The importance of noncognitive symptoms in AD is well known to clinicians, but has been played down by the US Food and Drug Administration: only recently have outcome variables addressing improvement in functional autonomy and behavior been added to the list of scales used AD drug trials. For instance, the McGill-developed Disability Assessment in Dementia scale measuring activities in daily living has been used with success in recent studies using the CI metrifonate (data not yet published), whereas the M1 agonist xanomeline has been shown to delay the appearance of disruptive neuropsychiatric symptoms using the Treatment Emergent Signs and Symptoms approach (8).

The few drugs that have received regulatory approval to this date include tacrine (Cognex), donepezil (Aricept) and rivastigmine (Exelon), all three being CI and thus working through enhancement of residual acetylcholine activity, which is more and more severely depleted as the disease unfolds. These agents are not expected to be clinically effective in late stages of $A D$ based on this mechanism of action, but studies are under way to establish this once and for all, with outcome variables appropriate for this stage of illness (9). Practice guidelines are beginning to emerge on how best 
Table 1. Transmitter replacement therapy in Alzheimer's and Parkinson's diseases.

\begin{tabular}{lcc}
\hline \hline & Alzheimer & Parkinson \\
\hline Targeted transmitter & acetylcholine & dopamine \\
Precursor approach & choline, lecithin & levodopa \\
Enhancement of release & linopirdine & amantadine \\
Slowing down of breakdown & tacrine, donepezil & tolcapone \\
Receptor stimulation & xanomeline & bromocriptine \\
\hline \hline
\end{tabular}

to use these drugs aimed at control of symptoms $(1,10)$. New issues are beginning to emerge from the availability of these drugs, such as when to initiate treatment and when to stop (11): a clear diagnosis of $\mathrm{AD}$ must be established and treatment of all concomitant disorders, particularly depression, must be done prior to prescription of a CI, and if there is clear evidence of deterioration despite therapeutic levels of a CI, it must be stopped. Is it possible to predict which patients will improve? Some evidence suggest that the apolipoprotein E genotype may allow such prediction, with patients carrying the epsilon 4 allele being the least responsive to drugs such as tacrine because of their severe depletion of ChAT relative to patients not carrying the epsilon 4 allele (12).

As in the pharmacological treatment of PD, combinations of drugs acting on different components of synaptic activity would theoretically be appropriate: a CI could be combined with a M1 agonist with careful attention to additive side-effects such as bradycardia, sweating, nausea, diarrhea and vomiting. It is also possible that drugs which have not demonstrated significant effects on their own (as monotherapy) will have a synergistic action in combination with other drugs: the acetylcholine releasing agent linopirdine may very well enhance the clinical effects of a CI such as donepezil.

\section{NON-CHOLINERGIC SYMPTOMATIC THERAPY}

Other neurotransmitters are depleted in AD such as noradrenaline, serotonin and somatostatin (13). Many studies have attempted to demonstrate a clinically and

Table 2. Disease-modifying therapies for Alzheimer's disease.

\begin{tabular}{|c|c|c|}
\hline $\begin{array}{l}\text { Neurodegenerative } \\
\text { process }\end{array}$ & $\begin{array}{l}\text { Pharmacologic } \\
\text { intervention }\end{array}$ & Example of drugs \\
\hline $\begin{array}{l}\text { amyloid deposition } \\
\text { apoptosis } \\
\text { calcium influx } \\
\text { excitotoxicity } \\
\text { inflammation } \\
\text { oxidative stress } \\
\text { oxidative stress }\end{array}$ & $\begin{array}{l}\text { anti-aggregants } \\
\text { neurotrophic factors } \\
\mathrm{Ca}^{2+} \text { channel blockers } \\
\text { glutamate antagonists } \\
\text { anti-inflammatory } \\
\text { anti-oxidants } \\
\text { MAO-B inhibitors }\end{array}$ & $\begin{array}{l}\text { (preclinical) } \\
\text { cerebrolysine } \\
\text { nimodipine } \\
\text { milacemide } \\
\text { COX-2 inhibitor } \\
\text { alpha-tocopherol } \\
\text { selegiline } \\
\text { lazabemide }\end{array}$ \\
\hline
\end{tabular}

statistically significant effect, but so far results have been disappointing, even with agents having multiple neurotransmitter augmenting properties such as besipirdine (data not published).

Propentofylline is under regulatory review for its symptomatic effects in $\mathrm{AD}$ as well as in vascular dementia, acting through multiple mechanisms including inhibition of $\mathrm{Na}^{+}$-independent adenosine transporters and of cyclic nucleotide phosphodiesterases, while reducing microglial activation (14).

Despite the difficulties in developing effective and safe non-cholinergic symptomatic drugs for $\mathrm{AD}$, this effort is imperative considering the relative few patients improving on CI monotherapy, estimated to be 30 to $60 \%$ depending on study duration (usually six months) and whether one considers an improvement over baseline or a lack of deterioration a criteria for response to therapy. The concept of pharmaco-genetics derived from analysis of the tacrine data base (12) suggest that $\mathrm{AD}$ patients carrying the apolipoprotein $\mathrm{E} 4$ genotype would respond better to non-cholinergic drugs.

\section{SLOWING PROGRESSION}

The concept of slowing progression by modifying the underlying neurodegenerative mechanisms in $\mathrm{AD}$ is attracting more and more interest (15), and would be clinically very relevant in early stages of AD. Recent advances in our understanding of primary (such as amyloid deposition) and secondary (such as microglial activation (16)) mechanisms are leading to a number of etiology-based therapies, the main focus being on antioxidant and anti-inflammatory agents (Table 2).

The methodology to prove that a given treatment slows down progression is different from that of symptomatic benefit and different trial designs have been suggested, ranging from randomized start to double-blind withdrawal maneuver (17). The time to reach a clinical milestone such as loss of autonomy, institutionalization or death has been tested successfully with alpha-tocopherol and selegiline in later stages of $\mathrm{AD}$ (18), and time to change from minimal cognitive impairment to diagnosable dementia is under study (6). Longer studies (minimum of two to three years) and large numbers of subjects are required, but the impact on AD could be immense, particularly if safe and effective therapy could delay appearance of symptoms in genetically predisposed individuals.

\section{PREVENTION}

The concept of delaying appearance of AD symptoms as a prevention strategy was introduced by Katchaturian in 1992 as "the five-five, ten-ten plan for AD": given that 
Table 3. Potential preventive approaches for Alzheimer's disease

\begin{tabular}{ll}
\hline \hline Low risk & $\begin{array}{l}\text { anti-oxidant agents, } \\
\text { estrogens in women }\end{array}$ \\
Moderate risk & anti-inflammatory agents \\
High risk & gene modifying proteins \\
All & control of systolic hypertension \\
\hline \hline
\end{tabular}

the prevalence of AD doubles every five years beyond age 65 , delaying the appearance of symptoms by five years would result in a $50 \%$ reduction in prevalence in one generation, since people would die of other causes. Delaying the onset by ten years would again half the prevalence, reducing it by $75 \%$ in one generation (19).

The methodology for proving that an intervention delays the appearance of AD symptoms is complex and costly, but not impossible (20). For example, a cohort of 2500 persons over age 75 per treatment group studied over 5 years would allow for an $80 \%$ probability of detecting a $30 \%$ decrease in disease incidence, the end point being a clinically recognized dementia.

Choices of treatment include anti-oxidants and antiinflammatory drugs, and, possibly for women, estrogens. Indeed, a number of biological and clinical observations suggest an important role for estrogens in neuronal repair and cognitive enhancement (21). The potential equivalent in men would be dehydroepiandrosterone.

Data generated from large scale epidemiological studies, such as the Canadian Study of Health and Aging, have demonstrated a number of risk factors towards $\mathrm{AD}$, such as increasing age, a positive family history of dementia, low education and systolic hypertension, whereas protective factors that may be applicable to the population as a whole include higher education, long term use of anti-inflammatory drugs and long term estrogen replacement therapy in postmenopausal women (22). The second (incidence) phase of this study has been completed and new factors may emerge. We are not far from the possibility of the biological and clinical assessment of middle age persons for their risk of developing AD in later life, and making recommendations for a preventive approach (Table 3) (23).

\section{CONCLUSION}

There has been steady progress in the treatment of $\mathrm{AD}$, with a recent emphasis on slowing of disease progression and potentially delaying it long enough in later life to significantly reduce its prevalence. Our understanding of the symptomatic benefit from cholinergic therapy is rapidly accelerating.
Integration of basic sciences and clinical research is essential for further advances in this complex illness.

\section{REFERENCES}

1. Gauthier S, Panisset M, Nalbantoglu J, Poirier J. Alzheimer's diseae: current knowledge, management and research. Canadian Medical Association Journal 157(8):1047-1052; 1997.

2. Small GW, Rabins PV, Barry PP et al. Diagnosis and treatment of Alzheimer disease and related disorders. Consensus statement of the American Association for Geriatric Psychiatry, the Alzheimer's Association, and the American Geriatrics Society. Journal of the American Geriatric Associaton 278(16): 1363$1371 ; 1997$.

3. Aubert I, Araujo DM, Cecyre D et al. Comparative alterations of nicotinic and muscarinic binding sites in Alzheimer's and Parkinson's diseases. Journal of Neurochemistry, 58:529-541, 1992.

4. Giacobini E, Pharmacokinetic and pharmacologic considerations. In: Pharmacotherapy of Alzheimer's Disease. Gauthier S, ed., London: Martin Dunitz Ltd;1998: In press.

5. Gauthier S, Bouchard R, Lamontagne $\mathrm{A}$ et al. Tetrahydroaminoacridine - lecithin combination therapy in patients with intermediate-stage Alzheimer's disease. New England Journal of Medicine 322(18):1272-1276; 1990.

6. Grundman M, Thal LJ. Trial designs. In: Pharmacotherapy of Alzheimer's Disease. Gauthier S, ed., London: Martin Dunitz Ltd;1998: In press.

7. Rockwood K, Beattie BL, Eastwood MR et al. A randomized, controlled trial of linopirdine in the treatment of Alzheimer's disease. Canadian Journal of Neurological Sciences 24(2):140145; 1997.

8. Bodick NC, Offen WW, Levey AI et al. Effects of xanomeline, a selective muscarinic receptor agonist, on cognitive function and behavioral symptoms in Alzheimer's disease. Archives of Neurology 54(4): 465-473; 1997.

9. Panisset M, Gauthier S. Outcome variables in research and in practice. In: Pharmacotherapy of Alzheimer's Disease. Gauthier S, ed., London: Martin Dunitz Ltd;1998: In press.

10. Murali Doraiswamy P. Current cholinergic therapy for symtoms of Alzheimer's disease. Primary Psychiatry 3: 3-11; 1996.

11. Gauthier S, Poirier J. Achievements and unresolved issues. In: Pharmacotherapy of Alzheimer's Disease. Gauthier S, ed., London: Martin Dunitz Ltd; 1998: In press.

12. Poirier J, Delisle MC, Quirion R et al. Apolipoprotein E4 allele as a predictor of cholinergic deficits and treatment outcome in Alzheimer's disease. Proceedings of the National Academic of Sciences USA 92(26):12260-12264, 1995.

13. Feldman H, Gracon S. Alzheimer's disease: symptomatic drugs under development. In: Clinical Diagnosis and Management of Alzheimer's Disease. Gauthier S, ed., London: Martin Dunitz Ltd; 1996: 239-259.

14. Rudolphi KA. Propentofylline - preclinical data. In Alzheimer Disease: From Molecular Biology to Therapy. Becker R, Giacobini E, eds., Boston: Birkhäuser; 1996: 355-359.

15. Aisen PS, Davis KL. The search for disease-modifying treatment for Alzheimer's disease. Neurology 48(5 suppl 6): S35-S41; 1997.

16. McGeer EG and McGeer PL. Innate Inflammatory Reaction of the Brain in Alzheimer Disease. McGill Journal of Medicine 3(2): 134-141; 1998.

17. Leber P. Slowing the progression of Alzheimer disease: methodologic issues. Alzheimer Disease and Associated Disorders 11(suppl 5): S10-S21; 1997.

18. Sano M, Ernesto C, Thomas RG et al. A controlled trial of 
selegiline, alpha tocopherol, or both as treatment for Alzheimer's disease. New England Journal of Medicine 336(17): 1216-1222; 1997.

19. Khachaturian Z. The five-five, ten-ten plan for Alzheimer's disease. Neurobiology of Aging 13(2): 197-198; 1992.

20. Thal LJ, Carta A, Doody R et al. Prevention protocol for Alzheimer disease. Position paper from the International Working Group on Harmonization of Dementia Drugs Guidelines. Alzheimer Disease and Associated Disorders 11(suppl 3): 46-49; 1997.

21. Birge SJ. The role of estrogen in the treatment of Alzheimer's disease. Neurology 48(5 suppl 7): S36-S41; 1997.

22. Canadian Study of Health and Aging. The Canadian Study of Health and Aging: risk factors for Alzheimer's disease in Canada. Neurology 44(11): 2073-2080; 1994.

23. Gauthier S. Prevention of Alzheimer's disease. Annales de Médecine Interne In press; 1998.

Serge Gauthier, M.D., is a neurologist with special interest in the treatment of Alzheimer's disease. After his M.D. degree at the Université de Montréal (Montreal, Quebec, Canada), he completed his Neurology training at McGill University (Montreal, Quebec, Canada) followed by a MRC Scholarship with Professor Theodore L, Sourkes. After ten years as Director of the McGill Centre for Studies in Aging (Montreal, Quebec, Canada), he is currently a recipient of a MRC/PMAC Senior Scientist Award. 